\title{
Temuan Gerabah di Situs Wonoboyo
}

\section{Selarti Venetsia Saraswati}

Keywords: pottery, Hindu-Buddha, ceramic, classical, archaeology

\section{How to Cite:}

Saraswati, S. V. Temuan Gerabah di Situs Wonoboyo. Berkala Arkeologi, 13(3), 1226. https://doi.org/10.30883/jba.v13i3.613

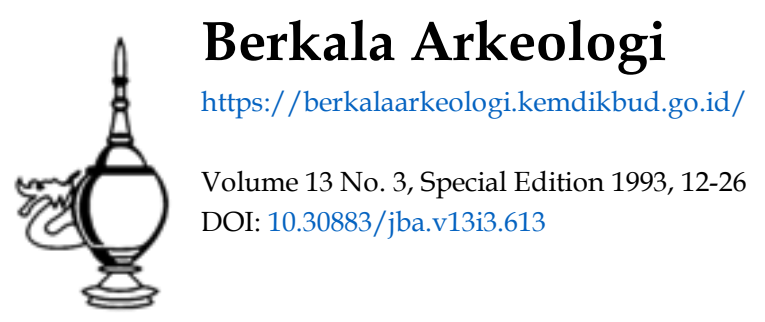

\section{(c) (i) (2) (2)}

This work is licensed under a Creative Commons Attribution-NonCommercial-ShareAlike 4.0 International License. 


\title{
TEMUAN GERABAH DI SITUS WONOBOYO
}

\author{
Otoh: \\ Selarti Venetsla Saraswati
}

\section{1. pendahuluan}

Situs Wonoboyo pertama kall menarlk perhatlan kalangan arkeologls maupun masyarakat karena di situs inl ditemukan sejumlah benda emas dan perak pada tahun 1990. Sejak penemuan emas tersebut, di situs ini telah dilakukan beberapa kall survel maupun ekskavasi, balk dalam kaitannya dengan penyelamatan maupun penelitian. Salah satu aspek yang akan dibicarakan dalam tulisan Ini adalah hasil dari penggalian penyelamatan maupun penelitian yang berupa iemuan gerabah. Temuan gerabah dari situs Wonoboyo pada tahap penggalian penyelamatan menghasilkan asumsl bahwa situs Wonoboyo merupakan situs pemukiman (Subroto, 1991:4).

Secara khusus tekanan pada tulisan ini adalah temuan gerabah hasil penslitian tahap $V$ di situs Wonoboyo yang dilakukan oleh Balai Arkeologi Yogyakarta. Sebagai latar akan disinggung pula temuan gerabah hasil penggallan sahap-tahap sebelumnya untuk mendapatkan gambaran yang lebih jelas mengenai temuan gerabah tersebut.

Temuan gerabah pada suatu situs dapat menunjukkan berbagal aspek dari situs tersebut, sebab artefak, dalam hal inl gerabah, dikembangkan oleh manusia dengan maksud tertentu atau karena kepercayaan yang dimiliki (Joukowsky, 1980:276).

Sebagal contoh misalnya dari temuan gerabah dapat dlketahui karakter situs, aktivitas yang pernah terjadi di situs, maupun stratifikasl sosial pada situs. Dalam kaitannya dengan situs Wonoboyo, tentu saja temuan gerabah mempunyal nllai yang cukup penting bila disejajarkan dengan temuan lain dari situs ini, sebab data gerabah dapat mendukung penafsiran tentang intensitas penghunlan situs.

Intensitas penghunian situs Wonoboyo dalam hal Inl akan ditinjau darl segl kuantltatlf maupun kualltatlf temuan gerabahnya. TInggl rendahnya Intensitas penghunlan situs Wonoboyo tldak dapat dllinat tanpa membandlngkannya dengan situs-situs sejenls darl masa klaslk. Oleh karena ltu akan dillhat perbandingan antara kepadatan 
temuan gerabah dan ragam bentuknya di situs Wonoboyo dengan beberapa sltus pembanding.

\section{TEMUAN GERABAH hasIL PENELITIAN WONOBOYO}

Penelltlan yang dllaksanakan dl sltus Wonoboyo menghasilkan sejumlah data arkeologls, yang berupa artefak, ekofak, serta fitur. Temuan artefak dapat dipllahkan menjadl dua, yaltu artefak lepas dan struktur atau unsur bangunan. Temuan ekofak berupa arang, serta fltur yang ditemukan berupa jejak daun, bercak warna gelap, pembusukan kayu, dan lubang sillnder.

Temuan gerabah sebagai salah satu jenis temuan artefak lepas yang khusus akan diamati dalam makalah ini, ditemukan fragmenter dalam bentuk pecahan sisa wadah. Dari berbagai tahap penelltlan belum ditemukan bentuk utuhan atau sete-ngah utuh, yang dapat mengacu pada suatu bentuk wadah, maupun fungsi wadah semula. Adanya usaha rekonstruksi dari beberapa fragmen gerabah yang ditemukan, belum dapat menunjukkan suatu bentuk asal wadah, seperti yang dilaksanakan pada penelitlan tahap III (Anonim, 1992 : 65). Pembahasan mengenal temuan geraban dari situs Wonoboyo akan dllakukan per tahap penelititan yang telah dllakukan di sltus tersebut.

\section{A. Tomuan Gerabah Ekskavasi Wonoboyo Tahap I.}

EkskavasI Wonoboyo tahap I dllaksanakan oleh Kantor Suaka Peninggalan Sejarah dan Purbakala Propinsı Jawa Tengah dan Jurusan Arkeologl Fakultas Sastra Unlversitas Gajah Mada. Ekskavasl yang dllaksanakan darl tanggal 5 sampal dengan 9 November 1990. menghasilkan tujuh kotak ekskavasl serta satu lubang ujl (test pit). Data arkeologls dljaring darl ekskavasl serta survel pengamatan muka tanah.

Laporan hasll ekskavasI tahap I menyebutkan temuan gerabah hasll ekskavasl sejumlah 29 fragmen, yang terdlrl darl 22 fragmen badan wadah dan 7 fragmen teplan wadah (Kantor SPSP Jateng dan Jur. Arkeologl FS-UGM, 1990a : 15). Temuan tersebut dldapatkan darl dua kotak ekskavasl, yaltu kotak B4 pada kedalaman splt (4) sejumlah 21 fragmen badan dan 7 fragmen teplan wadah, serta sebuah tragmen badan darl kotak A5 pada kedalaman splt (5).

Uralan anallsls hasll ekskavasI pada bab III tidak menyebutkan 
secara rinci penanganan gerabah hasil penelltian, hanya dlsebutkan bahwa ketujuh fragmen blblr wadah terdirl atas dua tlpo. Demiklan pula darl hasll survel muka tanah of slsl barat laut dusun Plosokuning pada sisa galian sumur baru, dlungkapkan adanya temuan gerabah yang cukup banyak serta temuan tragmen tulang blnatang yang belum dlklastilkasl.

\section{B. Temuan Gerabah Ekskavasl Wonoboyo Tahap II.}

Ekskavasi tahap II InI dilaksanakan pula oleh Kantor Suaka Peninggalan Sejarah dan Purbakala Propinsi Jawa Tengah, yang bekerja sama dengan Jurusan Arkeologl Fakultas Sastra Unlversltas Gajah Mada. Ekskavasi dilaksanakan selama 10 hari, yaitu dari tanggal 10 sampal dengan 19 Desember 1990 dan menghasilkan 23 kotak ekskavasi.

Berdasarkan penulisan laporan analisis temuan non-struktural keramik lokal, disebutkan adanya temuan sejumlah 317 iragmen gerabah dari hasil ekskavasi serta 1 buah darl permukaan tanah. Sejumlah temuan gerabah tersebut berdasarkan klasiflkasi terdirl atas 44 fragmen teplan, 257 fragmen badan, 1 fragmen leher, dan 15 fragmen dasar. Temuain gerabah tersebut didapatkan pada 8 kotak ekskavasl, yaitu kotak i'41, x'7, x'47, a"45, b"47, e"46, r"38, dan r"45 (Kantor SPSP Jateng dan Jur. Arkeologl FS-UGM, 1990 b : 55).

Pemerian data leb/h lanjut menyebutkan bahan dasar gerabah tanah liat dengan temper pasir, dengan pembakaran bagus walaupun beberapa fragmen terlihat ada reduksi. Cara pembuatan menggunakan roda putar, dengan beberapa fragmen terlihat diberi slip merah. Teknik hias berupa garis-garis dengan cara diupam dan digores. Ketebalan gerabah yang ditemukan berkisar antara $1,7 \mathrm{~cm}$ hingga 2,5 $\mathrm{cm}$. Interpretasi data berdasarkan bentuk fragmen teplan, badan. leher dan dasar merupakan bagian dari Jambangan, kuali besar dan kecll, piring/cowek, tempayan dan kendl. Pengamatan sisa pemakalan pada beberapa gerabah menunjukkan adanya jelaga.

Berdasarkan laporan ekskavasI tahap II Ini, terutama pada penjelasan bab II pada Deskripsi Hasll Ekskavasi, temuan yang dapat dirincl adalah sejumlah 52 gerabah yang terdirl atas 16 fragmen teplan, 29 fragmen badan, 1 fragmen cerat, 1 fragmen pundak dan 5 
fragmen dasar (Ib/d., 8-44).

\section{Tomuan Gorabah Ekskavasl Wonoboyo Tahap III.}

EkskavesI Wonoboyo tahap III diselenggarakan oleh Sub Direktorat Perlindungan Direktorat Perlindungan dan Pembinaan Peninggalan Sejarah dan Purbakala. Penelitian berlangsung selama 10 harl, yaltu pada tanggal 19 sampal dengan 27 September 1991, dan berhasll membuka 22 kotak ekskavasl.

Analisis temuan artefak lepas yang berupa gerabah dllakukan terhadap 71 fragmen gerabah yang cukup bervarlasi dari segi kualitas bahan, teknologi, bentuk dan fungsinya. Dari pemerian hasil ekskavasl dapat dirincl sejumlah 35 fragmen darl 12 kotak ekskavasi. Anallsis yang dilakukan terhadap temuan gerabah pada penelitian tahap inl menghasilkan 3 kelompok gerabah berdasarkan ketebalannya. Pengelompokan tersebut dapat dirincl sebagai berikut (Anonim, 1992 : 65-68)

\section{Gerabah tipis.}

Pada kelompok Ini ketebalan gerabah berklsar antara $0.20 \mathrm{~cm}$ $0.50 \mathrm{~cm}$, dengan pengerjaan sampai pada pembakarannya cukup sempurna, sehingga menghaslikan gerabah yang halus. Beberapa fragmen menggunakan slip warna merah. Sebagian jenis kelompok Inl ditemukan pula dibuat lebih kasar, terlihat dari temper dan porositas yang tinggl. Gerabah tipls inl ditemukan sangat fragmenter sehingga sullt untuk diketahul identifikasi bentuknya.

2. Gerabah sedang.

Ketebalan gerabah pada kelompok Inl berklsar antara $0.50 \mathrm{~cm}$ hingga $0.70 \mathrm{~cm}$. Gerabah dengan ukuran ketebaian sedang $\mid \mathrm{nl}$ dipliahkan menjadl dua Jenis, yaitu gerabah halus dan gerabah kasar. Gerabah halus menggunakan bahan yang halus, beberapa fragmen dlantaranya menggunakan slip warna merah pada dua sisinya, dan dibuat dengan teknlk roda putar cepat. Gerabah kasar menggunakan temper pasir dan mungkin kapur berbutir besar. Slip pada umumnya hanya terdapat pada satu slsl, dan teknik pembentukan menggunakan paduan roda putar lambat dan 
pelandas pada baglan dalam. Pengamatan baglan toplan pada gerabah kasar Inl mempunyal bentuk mulut setengah terbuka atau vertikal, yang dildentlkkan dengan baglan Jenis wadah perluk. Salah satu bentuk teplan yang mewakll wadah leb/h terbuka dildentilikasikan darl sejenls mangkuk atau plring.

\section{Gerabah tobal.}

Ketebalan gerabah inl berklsar antara $0.70 \mathrm{~cm}$ hingga $2 \mathrm{~cm}$. Gerabah tebal InI dipllahkan menjadl dua jenis pula, yaltu gerabah yang dlhaluskan dua sisinya dan yang dihaluskan satu sisl saja. Gerabah yang dihaluskan dua sisi merupakan wadah yang terbuka dengan diameter mulut wadah yang ada $27 \mathrm{~cm}$. Mellhat bentuk tepiannya, mungkin sekall fragmen tersebut sebagal bagian dari wadah tempayan atau gucl yang tldak berleher. Beberapa fragmen menunjukkan adanya penghalusan permukaan dengan dlupam, dan bekas usapan kaln untuk menghaluskan gerabah membuktikan penggunaan roda putar cepat. Gerabah dengan penghalusan satu sisi umumnya mempunyal sisi luar yang halus dan sisl dalam yang berlekuklekuk sebagal akibat pembentukan dengan tangan atau penggunaan pelandas. Hampir dapat dipastlkan pembuatan jenis gerabah semacam ini menggunakan roda putar lambat yang dipadukan dengan teknlk tekan tangan atau pelandas. Gerabah tebal ini terbuat darl bahan bertekstur kasar dengan pasir sebagal temper yang dominan. Tampak pula penggunaan slip warna merah atau coklat tua untuk memoles sisl luar. Dari salah satu temuan baglan dasar yang berdlameter sekitar $50 \mathrm{~cm}$, dlperkirakan berasal dari bentuk wadah tempayan besar.

Apablla dillhat darl segl dekorasi, temuan gerabah tahap ekskavasl III InI tidak cukup bervarlasl. Satu fragmen gerabah dltemukan berhias berupa garis-garis silang, yang dlbuat dengan teknlk tatap dan menggunakan slip. Salah satu temuan yang menarik adalah tragmen gerabah yang berbentuk cakram (d/scolo) yang ditemukan pada kotak $x^{\prime} 46$. Berdasarkan perbandingan bentuk dengan gerabah dl tempat lain, bentuk Inl merupakan baglan darl kendl berpayung dan pecahan berbentuk cakram Inl adalah baglan payungan kendl tersebut. 
Analisis fungsi dart gerabah yang diternukan pada okskavasi tahap III InI belum dapat dllakukan, oleh karena temuan yang ada belum mencukupl untuk dapat direkonstruksi sohingga tidak daps: dipastikan apakah temuan gerabah bertungsi teknomik, sosloteknlk atau ldeoteknlk. Kecenderungan gerabah-gerabah tersebut beffungsl toknomik dimungkinkan berdasarkan konteks temuannya.

\section{Tomuan Gorabah Ekskavasl Wonoboyo Tahap IV.}

Ekskavasi tahap IV diselenggarakan oleh Jurusan Arkeologi Fakultas Sastra Universitas Gajah Mada pada bulan Oktober 1991. Penyelenggaraan penelittan inl bersifat latihan ekskavasl bagi mahasiswa jurusan Arkeologi. Hasll ekskavasi tahap IV InI thak diblcarakan di sinl, karena laporan penelitian leblh bersifat intern.

\section{E. Tomuan Gorabah Ekskavas! Wonoboyo Tahap V.}

Ekskavasl Wonoboyo tahap $V$ dilaksanakan oleh Balal Arkeologl Yogyakarta selama 10 harl, yaitu pada langgal 5 sampal dengan 14 Desember 1991. Penjaringan data dilakukan melalul observasi pada kotak-kotak tahap penellttan sebelumnya, dan ekskavasi dilakukan berdasarkan informasl yang dihasilkan oleh hasil observasi tersebut. Kotak ekskavasi yang dibuka pada tahap Ini sejumlah lima buah, yaitu kotak $113, x^{\prime} 6,9^{\prime \prime \prime 29,}$ j"'11, dan $0^{\prime \prime \prime 5} 5$.

Tahap anallsis data bagi unit analisis artefak diupayakan untuk dapat mengidentifikasikan pola pengklasteran artetak berdasarkan varlabel stllistlk, formal serta kemik (TIm Penelltlan Ekskavasi Wonoboyo, 1991: 5). Prosedur analisis gerabah yang dllakukan adalah melakukan klasifikasl ulang atau pemilahan hasil perokaman data lapangan, yang dikuti dengan usaha pengamatan pada bentuk kenampakan ilsik gerabah. Pemllahan yang dilakukan pada temuan gorabah Ini dapat pula disebut sebagal pemilahan buatan (artiflcial classification), yaltu pomilahan yang dibuat untuk disusun berdasarkan kepentingan dan kemudahan penellit ( Sharer and Ashmore, 1980:278). Pengamatan inl diupayakan akan dapat mengungkapkan aspek bentuk, teknologl, serta gaya (st!listlk) gerabah.

Gerabah yang drdapatkan pada tahap penelttlan $\mathbf{V}$ hanya oltemukan pada empat kotak okskavast, dan di kotak P13 tlak 
ditemukan tragmen gerabah. Secara keseluruhan temuan yang dldapatkan pada empat kotak ekskavasl berjumlah 233 fragmen, yang terdirl darl pecahan baglan teplan sejumlah 48 fragmen, baglan leher 5 fragmen, baglan karinasl 12 frgamen, baglan cerat 3 fragmen, baglan tutup 1 fragmen, baglan badan 160 tragmen, serta baglan dasar 4 tragmen. Darl sejumlah temuan tersebut hanya 72 fragmen yang mendapat penanganan secara khusus, dalam artl sejumlah temuan tersebut dapat dlanggap mewaklli keseluruhan temuan guna identlflkasl bentuk serta fungsl gerabah. Temuan seleblhnya, yaltu sejumlah 161 fragmen yang terdiri dari 160 fragmen badan tidak dapat untuk dijadikan sampel analisis guna rekonstruksi bentuk serta fungsi gerabah, dan 1 fragmen dasar dari kotak 0"'57 ditemukan pada permukaan kotak ekskavasi. Hasll analisis bentuk gerabah dari sejumlah 72 fragmen, hanya 71 tragmen yang dapat diketahui bentuk asalnya, dan 1 fragmen tldak dapat diidentifikasikan oleh karena pecanannya sangat kecil. Sejumlah temuan tersebut didapatkan hanya pada dua kotak ekskavasi, yaitu pada kotak 9"m29 dan kotak j"'11. Temuan pada kotak $x^{\prime} 6$ tidak dilakukan analisis oleh karena keseluruhan temuan terdiri dari fragmen badan. Tabel bentuk gerabah yang ditemukan pada dua kotak tersebut adalah sebagai berikut :

\begin{tabular}{|c|c|c|c|}
\hline BENTUK & KOTAK g्29 & KOTAK F11 & JUMLAY PECAMAN \\
\hline Pirlng & - & 1 & 1 \\
\hline Mengkuk & 1 & 3 & 4 \\
\hline Paou & - & 5 & 6 \\
\hline Poriuk & 2 & s & 5 \\
\hline Bolenga & - & 2 & 2 \\
\hline Buyung & 3 & 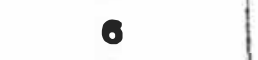 & 9 \\
\hline domberpen & 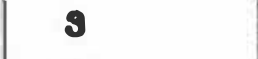 & 6 & $\bullet$ \\
\hline Tempayen & 13 & 13 & 26 \\
\hline Kendl & - & 7 & 7 \\
\hline Copuk & - & 2 & 2 \\
\hline Tungkut & 1 & . $\quad$ - & 1 \\
\hline JUMLAH & 28 & 48 & 71 \\
\hline
\end{tabular}

Pengamatan terhadap tipe teplan wadah secara umum dapat dibedakan menjadl empat, yaltu tepian wadah terbuka, teplan wadah 
tertutup, teplan wadah tegak, dan teplan wadah berleher tinggl. Berdasarkan data yang diperoleh sebagal hasil anallsis sampel yang terkumpul, dapat dluralkan atribut tpe wadah tersebut di atas.

\section{Piring}

Bentuk terbuka lebar, dengan diameter $16 \mathrm{~cm}$ dan tebal $2,1 \mathrm{~cm}$. Wadah piring yang hanya ditemukan satu buah berasal darl fragmen baglan dasar gerabah InI mempunyal fungsi pemakaian sangat beragam. Penafsiran sementara berdasarkan pengamatan orientasl bentuk dapat berfungsi sebagal alas makan, alas sayur, cobek, atau tutup wadah (kekep). Penyelesalàn permukaan wadah tidak dapat diamati secara jelas oleh karena telah aus dan mengalami sementasi oleh matriks sekitarnya. Teknik pembentukan menggunakan roda putar lambat dengan porusitas sedang, dan menggunakan campuran bahan berupa pasir dengan butiran sedang.

\section{Mangkuk}

Wadah ini termasuk tipe tepian wadah terbuka dengan orientasi tepian dan ujung blbir bervariasi tegak dan mendatar. Diameter wadah yang ditemukan berukuran $13 \mathrm{~cm}$. Penyelesaian permukaan luar dan dalam menggunakan slip warna merah, 3 buah fragmen menunjukkan adanya pengupaman pada bagian luar. Teknlk pembentukan menggunakan roda putar cepat yang ditunjukkan adanya Jejak strlasl merata pada baglan dalam. Campuran bahan pembentuknya berupa pasir dengan butiran halus hingga sedang. Salah satu fragmen dart wadah ini mempunyal hlasan dengan teknlk gores motlf sirip Ikan.

\section{Pasu}

Bentuk wadah terbuka dengan orlentasi teplan dan ujung blblr mendatar dan menurun. Baglan dasar agak cembung . baglan badan bervarlasl cembung, rata togak, dan bersudut (karlnasl patah). Dlameter wadah berklsar 26 - $32 \mathrm{~cm}$. Temper yang dlgunakan pasir kasar, bercampur dengan butiran kapur. Tingkat porusitas agak tinggl, dan meskl sangat tipls masih dapat terlihat bekas 
pemakalan sllp pada stsi permukaan luar di baglan toplan dan sebaglan badan. Teknik -pembentukan menggunakan roda putar maupun gebungan dengan polandas.

\section{Porluk dan Bolanga}

Bentuk wadah tertutup dengan mulut kecll hingga sedang, diameter berklsar antara 12 - $28 \mathrm{~cm}$. Bentuk badan dan dasar membulat cembung, dengan panjang baglan badan bervarlasl tambun hingga panjang. Penafsiran sementara berdasarkan pengamatan bentuk wadah dilain tempat, tipe perluk, belanga, kendll, dan kuall dapat dimasukkan dalam satu tipe perluk, oleh karena orlentasi teplan dan blbir serta kontur bentuk wadah relatlf sama. Penyebutan masing-masing sub tlpe didasarkan atas ukuran, fungsl pemakalan, dan Juga Istllah penyebutan lokal. Temper yang digunakan pasir kasar hingga sedang, beberapa fragmen menggunakan campuran pasir kwarsa. Bekas pemakalan tampak pada baglan dasar gerabah, yaitu berupa jelaga. Tingkat porusltas sedang hlngga tinggl, dan teknik pembentukan dengan roda putar.

\section{Buyung}

Bentuk wadah tertutup dengan mulut kecll, dengan dlameter berklsar antara $10-14 \mathrm{~cm}$. Secara umum orlentasl teplannya hamplr sama demikjan pula variasl blblrnya. Bentuk dasar dan badan membulat cembung dengan leher pendek. Istllah lokal untuk buyung blasa disebut dengan klenting. Penyelesalan permukaan luar beberapa dlantaranya dengan sllp, upam atau penggabungan keduanya. Temper yang dlgunakan pasir kasar hingga sedang dengan porusltas tinggl, dengan teknlk pembentukan menggunakan roda putar.

\section{Jembangan}

Bentuk wadah terbuka, dengan diameter berklsar antara 30 hingga leblh darl $40 \mathrm{~cm}$. Wadah inl mempunyal bentuk lebar dl baglan atas, mengecll ke bawah dan bagian dasarnya rata. Untuk bentuk Inl dengan dlameter ukuran sedang dan bedan lebih pendek, biasa disebut pengaron Temper yang digunakan pasir dengan butiran 
kasar dan porusitas tinggl. Teknlk pembentukannya menggunakan roda putar dan tatap pelandas.

\section{Tempayan}

Bentuk wadah tertutup. dengan dlameter berkssar antara 18 - 25 $\mathrm{cm}$. Orientasi teplan maupun bibir hampir sama bentuknya, yaltu mendatar. Baglan badan bervarlasl cembung dan tegak, dengan bagian dasar rata. Tempayan ini pada beberapa daerah di Jawa sering disebut dengan gentong dan variasi iain berdasarkan fungsi ada pula yang disebut padasan. Perbedaạn keduanya hanya terletak pada ada tidaknya cerat yang berfungsi untuk mengalirkan air. Temper yang digunakan berupa pasir butiran kasar, tingkat porusitas tinggi, dan teknlk pembentukan menggunakan roda putar dan tatap pelandas.

Kendi

Bentuk wadah tertutup dengan orlentasi tepian tegak dan terbuka, dengan diameter berkisar antara 2,5 - $6 \mathrm{~cm}$. Berdasarkan pengamatan pada pecahan wadah ini, sekurangnya terdapat tiga tipe bentuk kendi, yaitu bercerat, tanpa cerat, dan mempunyai payungan pada bagian lehernya. Penyelesaian permukaan luarnya ada yang menggunakan slip warna merah, dan ada pula yang diupam. Temper yang digunakan pasir halus hingga sedang, porusitas rendah, teknik pembentukan menggunakan roda putar lambat.

\section{Cepuk}

Bentuk wadah terbuka dengan orientasi teplan terbuka, dengan diameter antara $9-14 \mathrm{~cm}$. Temper yang digunakan pasir dengan butiran sedang, dan tanpa penyelesaian permukaan luar maupun dalam. Porusitas sedang dan teknlk pembentukannya menggunakan roda putar lambat.

\section{Tungku}

Sebuah tragmen gerabah dildentifikasikan sebagal tungku berdasarkarkan baglan elemen penyangga wadah yang ditemukan. 
Pada tragmen ini terdapat sisa pemakalan yang berupa jelaga. Penggunaan tungku sebagal alat pemanas untuk memasak, menggunakan bahan kayu sebagal sarana menyulut apl. Temper yang dapat dlamati pada tragmen InI berupa pasir dengan butiran sangat kasar.

\section{PEMBahasan dan kesimpulan}

Berdasarkan hasll penelitian yang telah dllaksanakan pada keempat tahap penelitlan (di luar penelltlan tahap IV yang diselenggarakan oleh Jurusan Arkeologi FS-UGM), telah dibuka sejumlah 57 kotak ekskavasi dan 1 lubang ujl. Dari sejumlah kotak yang dlgali, hanya 25 kotak ekskavasi yang mengandung temuan gerabah, yang seluruhnya berjumlah 651 fragmen.

Pengamatan artefak gerabah yang ditemukan pada kotak ekskavasi keempat tahap penelitian menunjukkan berbagai ragam bentuk wadah yang menunjukkan tipe kegiatan kelompok dapur. Keglatan ini tidak hanya mencerminkan kegiatan utama yang berpusat dl dapur saja, tetapl mempunyal pengertian yang leblh luas, yaitu berkenaan dengan kegiatan memperoleh, memasak, mengolah, menyimpan dan menyajikan makanan dan minuman (South 1977:99). Pengamatan secara khusus pada gerabah tahap $V$ menunjukkan kualitas temuan yang biasa digunakan oleh kelompok masyarakai biasa, dalam arti bukan dari kelompox pemakal masyarakat penguasa atau bangsawan, yang blasanya menggunakan kualltas yang lebih balk dan raya. Meskipun demiklan beberapa fragmen gerabah menunjukkan teknlk, stillstlk, serta bahan yang lebih balk dibandingkan temuan gerabah lain, namun jumlahnya sangat sedikit, dan tidak dapat digunakan sebagal acuan pembanding.

Adanya keglatan bencana alam yang mengakibatkan situs Wonoboyo kuna terkubur, berpengaruh pula pada sisa artefak gerabah yang ditemukan. Sebagaimana diketahul, data arkeologi merupakan hasil proses transformasi dan hasil proses tingkah laku. Proses transformasi ini dapat melalul aktifitas manusia atau alam yang terjadi mulal pengendapan hingga ditemukan kemball (Sharer dan Ashmore 1980 : 78). Hamplr seluruh temuan gerabah hasil penelltian tahap $V$ menunjukkan gejala aus karena tererosl dan tertransportasi beberapa saat dan beradu dengan partikel bahan yang lebih keras. Hal 
Inl ditunjukkan dari kenampakan fisik sisl luar dan sudut-sudut luar pecahannye.

\section{TABEL RAGAM BENTUK GERABAH PERMUKAAN MASA KLASIK}

\begin{tabular}{|c|c|c|c|c|}
\hline RAGAM WADAH & Centen & Biting & Modono & Wonoboyo \\
\hline Copuk & + & & & + \\
\hline Mangkuk & + & + & + & + \\
\hline Cowek & + & & + & \\
\hline Wajan & + & & & \\
\hline $\begin{array}{l}\text { Piring } \\
\text { Layah }\end{array}$ & + & + & $\begin{array}{l}+ \\
+\end{array}$ & + \\
\hline Cawan & + & & & - \\
\hline Kekep/tutup & + & & + & \\
\hline Pinggan persegi & + & & & \\
\hline Pasu & + & + & & + \\
\hline Pindangan & + & & & \\
\hline Kendi & + & + & + & + \\
\hline Kendi bertutup & & + & & \\
\hline Bull-bull & + & & & \\
\hline Vas & + & + & + & \\
\hline Pol & & + & + & \\
\hline Jambangan & & & + & \\
\hline Kendil & + & & + & \\
\hline Cunvo & & + & + & \\
\hline Empluk & & + & & \\
\hline Kuali & + & + & + & \\
\hline Poriuk & + & + & & + \\
\hline Belanga & + & & & + \\
\hline Buyung & & + & & + \\
\hline Klenting & + & + & + & \\
\hline Dandang & + & & & \\
\hline $\begin{array}{l}\text { Genuk } \\
\text { Gentong }\end{array}$ & $\cdot$ & + & + & \\
\hline $\begin{array}{l}\text { Tompayan } \\
\text { Padasan }\end{array}$ & + & & + & + \\
\hline $\begin{array}{l}\text { Jembangan } \\
\text { Pengaron }\end{array}$ & + & + & + & + \\
\hline $\begin{array}{l}\text { Guol } \\
\text { Anglo }\end{array}$ & + & + & + & + \\
\hline Tungku & + & & + & + \\
\hline Jumlah & 22 & 17 & 19 & 12 \\
\hline
\end{tabular}


TABEL KEPADATAN TEMUAN gerabay

\begin{tabular}{|l|r|r|r|c|c|}
\hline Situs & Canban & Btoring & Mocowo & $\begin{array}{l}\text { Wonoboyo } \\
\text { Tahap III }\end{array}$ & $\begin{array}{c}\text { Wonoboyo } \\
\text { Tahap I, } \\
\text { II, III \& V }\end{array}$ \\
\hline Kotak Ekskavasi & 9 & 9 & 8 & 22 & 58 \\
Jumlah Temuan & 30.164 & 4.652 & 3.521 & 71 & 651 \\
Ragam Bontuk & 22 & 17 & 19 & 3 & 12 \\
Kepadatan Rata2 & 3.351 & 516 & 440 & 49 & 11 \\
\hline
\end{tabular}




\section{KEPUSTAKAAN}

Anonim. 1992. Laporan Keglatan Penentuan Batas Wllayah Cagar Budaya Dalam Rangka Penyelamatan Situs Wonoboyo. Bakosurtanal, Ditlinbinjarah dan Fakultas Geografl UGM. (tidak diterbitkan).

1990. Laporan Ekskavasi Penyelamatan Situs
Wonoboyo (5-9 Nopember 1990) Kantor Suaka
Peninggalan Sejarah dan Purbakala Propinsl Jawa Tengah dan
Jurusan Arkeologl FS-UGM. (tidak diterblłkkan).
1990. Laporan Ekskavasi Penyelamatan Situs
Wonoboyo (10-19 Desember 1990) Kantor Suaka
Peninggalan Sejarah dan Purbakala Propinsi Jawa Tengah dan
Jurusan Aikeologl FS-UGM. (tidak diterbitkan).

1991. Laporan Hasil Penasitian Arseolog Situs Wonoboyo. Tim Penelitian Arkeologi Situs Wonoboyo. Balai Arkeologl Yogyakarta. (tidak diterbitkan)

- 1990. Laporan Hasil Penelitian Arkeologi Situs Medowo IIL.Tim Penelltian Arkeologi Situs Medowo. Balai Arkeologi Yogyakarta. (tidak diterbltkan).

Joukowsky, Martha. 1980. A Complete Manual of Field Archaeology. New Jersey : Prentice Hall.

Novida Abbas dan Sunarto. 1990/1991. Laporan Penelitian Arkeologi Situs Biting, Lumajang, Jawa Timur, Tahap X 1990. Balal Arkeologl Yogyakarta. (tidak diterbitkan).

Sharer, Robert and Wendy Ashmore. 1980. Fundamentals of Archaeology. London:The Benjamnin/Cumming Publishing Company.

South, Stanley. 1977. Method and Theory In Historlcal 
Archaeology. New York: Academic Press.

Subroto, Ph. 1991. Benarkah Wonoboyo Bekas Sebuah Kraton?. Makalah pada Sarasehan di Kab. Klaten 5 September 1991.

TItl Surtl Nastitl dan Nurhadl Rangkuti. 1988. Laporan Penelitian Exskavasi Caruban, Lasem, Jawa Tengah. Berita Penelitian Arkeologi No. 38. Jakarta:Departemen Pendidikan dan Kebudayaan. 